\title{
Transitando entre dois estados, vou enganando-me e "passando a perna" no Estado burguês
}

\section{Transiting between two states, I'm fooling myself and "swinging my leg" in the bourgeois State}

\author{
Mariana Cunha Pereira*
}

Maria José Alves**

\section{Resumo}

\begin{abstract}
Este artigo pretende dialogar com as ideias do filósofo Antonio Gramsci sobre educação. A ideia é discutir, com base numa realidade concreta - a região de fronteira -, elementos da contra-hegemonia presente nas relações de ensino-aprendizagem. Para tanto, este texto apresenta as experiências de duas professoras, uma como profissional da educação básica da rede estadual de ensino do Tocantins, em município limítrofe com o estado de Goiás, e a outra como professora do ensino superior, que, ao realizar um trabalho de pesquisa de campo, intuiu o quão significativo seria um recorte investigativo sobre os aspectos da educação escolar naquela fronteira interna do Brasil. Trata-se de fronteira entre municípios de dois estados: Tocantins e Goiás. A metodologia faz uso de memória, análise de documentos e entrevistas dos pioneiros e professores mais velhos, ainda moradores daquela região. A narrativa se faz na primeira pessoa do plural para assumir um local de inserção naquele contexto e de coautoria. Trata-se, portanto, de um artigo que dialoga com autores das áreas de educação, antropologia, sociologia, história e geografia.
\end{abstract}

Palavras-chave: Educação. Estado. Fronteira. Goiás. Tocantins.

\section{Abstract}

This article aims to dialogue with the philosopher Antonio Gramsci's ideas on education. The idea is to discuss the basis of a concrete reality - the border region - elements of counter-hegemony present within teaching-learning relationships. Therefore, this work reflects the experiences of two teachers, one a professional primary educator from the state of Tocantin's school system, a neighboring municipality with the state of Goiás, and the other a higher education teacher that undertook research field work there, intuited significant as it would be an investigative recut on aspects of education within an internal border of Brazil. This is the border between the municipalities of two states: Tocantins and Goiás. The methodology makes use of memory, document analysis, and interviews of the older pioneers and teachers, and even the inhabitants of the region. The narrative is in the first person plural to assume an insertion place in that context and with co-authorship. It is, therefore, an article that will dialogue with authors of education, anthropology, sociology, history and geography.

Keywords: Border region. Education. Goiás. State. Tocantins.

Recebido em: 25/09/2016 - Aprovado em: 21/06/2017

http://dx.doi.org/10.5335/rep.v24i3.7766

Doutora em Antropologia Social da América Latina e Caribe - CEPPAC/UnB. Professora da Faculdade de Educação da Universidade Federal de Goiás. E-mail: mcunhap@yahoo.com.br

** Mestranda em Estudos da Linguagem da Universidade Federal de Goiás, Regional Catalão. Professora do Instituto Federal de Educação do Tocantins. E-mail: maria.alves@ifto.edu.br 


\section{Introdução}

Neste artigo, vamos discutir educação escolar sob a ótica de quem a vivencia no chão da escola, ou seja, professores, alunos e gestores que estão ou que já estiveram na ativa. Trata-se de buscar em suas falas as expressões do poder e do contrapoder que se forjam no cotidiano escolar. Para tanto, faz-se necessário um recorte da história local, que situa a região onde se localizam os municípios de fronteira interestadual da qual extraímos esta análise. Pensar a educação escolar na fronteira entre o norte de Goiás e o sul do Tocantins exige fazer uma retrospectiva da criação do estado do Tocantins.

Situado na Região Norte do Brasil, o estado do Tocantins reflete a mesma situação de desigualdade social e baixos índices de desenvolvimento humano característicos das Regiões Norte e Nordeste do país. Banhado pelos Rios Tocantins e Araguaia, de sul a norte, são esses os principais facilitadores da sobrevivência dos povos que habitam o estado. Os dois grandes rios foram, no passado, as principais vias de acesso ao vasto norte goiano, e a grande bacia hidrográfica que formam permite um amplo abastecimento de água durante todo o ano, inclusive nos períodos de seca típicos do Cerrado. Hoje, o Rio Araguaia atrai turistas fascinados pela pesca ou por suas extensas praias, enquanto o Rio Tocantins se tornou um dos principais fornecedores de energia hidrelétrica do país. Quando falamos dos tocantinenses, referimo-nos também a um contingente significativo de indígenas, cerca de seis mil pessoas de cinco etnias e alguns novos grupos indígenas que se autorreconheceram. Além desses, há os não indígenas, trabalhadores do campo que vivem da agricultura familiar, do trabalho assalariado nas áreas rurais, do comércio e dos empregos públicos que o estado e os municípios ofertam.

O Tocantins, anteriormente norte goiano, ao ser emancipado, em outubro de 1988, e elevado à condição de estado, nasceu "maduro", ou melhor, iniciou sua existência jurídica com todos os problemas socioeconômicos e políticos característicos de antigos estados já existentes no país. O estado tem como marco de seu desenvolvimento a rodovia BR-153, cuja finalidade é ligar o sul ao norte do Brasil. Às margens dessa rodovia, desenvolveram-se as cidades mais importantes do Tocantins no sentido político, populacional e econômico. No entanto, o que mais nos chama a atenção, quando se averigua os dados estatísticos, pós-construção da BR, é o aumento do fluxo migratório, intensificado nos anos 1980, 1990 e 2000, em especial, de povos oriundos do Nordeste brasileiro.

A região de fronteira entre os estados do Tocantins e Goiás apresenta um fluxo de continuidade de ações, relações comerciais, demandas entre os moradores e relações de vizinhança e de parentesco, fazendo com que, na maior parte do tempo, não 
se perceba o limite geográfico desses dois estados, exceto quando se faz necessário recorrer a regras que institucionalizam tais relações sociais. Talvez o que melhor explique essa situação foi-nos assim anunciado: "Em nossa região, é como se não houvesse separação nos dois estados, pois desfrutamos do que é mais acessível aos dois" (professora e ex-gestora de escola).

O olhar apurado dessa professora, que é moradora da região, conflui para o pensamento de autores que estudam o imaginário social de grupos. Para alguns autores, existe um imaginário social que caracteriza a fronteira como lugar do esvaziamento tanto físico quanto político, sendo o substrato dessa vivência o que importa. Ou seja, não é a demarcação geográfica que põe sentido às suas vidas, e sim os significados das relações sociais e culturais que são estabelecidas (FARAGE, 1991; SANTILLI, 2001; PEREIRA, 2006).

Tais observações puderam ser realizadas num período em que fazíamos uma incursão no campo, na cidade de Palmeirópolis, TO, em 2010. Assim, ao comparar a formação docente, constatamos que esse nível de ensino é mais avançado em Goiás do que no Tocantins, em virtude da maior oferta de ensino superior público em Goiás e também porque nesse estado as pesquisas na área de formação de professores já se consolidaram. Isso, sem dúvida, tem atraído os professores do Tocantins para Goiás, a fim de buscar sua capacitação docente, retornando ao estado de origem, logo depois, para o exercício de suas funções. Essa realidade é ilustrada pelo quadro de professores que se formou nas escolas das cidades fronteiriças nos últimos anos.

Uma das principais razões para essa migração é o fato de o Tocantins ser um estado novo, que oferta oportunidade de crescimento para a maioria dos recém-formados, posto que o salário da rede estadual, se comparado ao do estado de Goiás, é um atrativo que se mostrou considerável ao longo do período de implantação e consolidação do novo estado, conforme estudo realizado e evidenciado pela Figura 1 , a seguir. 
Figura 1 - Remuneração de professores no Brasil (40 horas-aula): ranking da rede estadual

\begin{tabular}{|c|c|c|c|}
\hline కक्ञ़ी Sindicato APEOC & \multicolumn{2}{|l|}{ RANKING } & सU ENE \\
\hline \multicolumn{4}{|c|}{ REDE ESTADUAL - REMUNERAÇÃO DOS PROFESSORES NO BRASIL (40 ha) } \\
\hline 07ㅇA AMAPÁ & $R \$ 2234,08$ & NORTE & (PDT) \\
\hline $08 \cap$ ALAGOAS & $R \$ 2030,00$ & NORDESTE & (PSDB) \\
\hline 09 TOCANTINS & $R \$ 2020,00$ & NORTE & (PMDB) \\
\hline 10 ESPÍRITO SANTO & $\mathrm{R} \$ 1920,00$ & SUDESTE & (PMDB) \\
\hline 11 SÃO PAULO & $\mathrm{R} \$ 1834,86$ & SUDESTE & (PSDB) \\
\hline 12 PARANÁ & $\mathrm{R} \$ 1798,54$ & SUL & (PMDB) \\
\hline 13 PARÁ & $\mathrm{R} \$ 1728,00$ & NORTE & (PT) \\
\hline 14 RIO DE JANEIRO & $\mathrm{R} \$ 1618,14$ & SUDESTE & (PMDB) \\
\hline $15 \circ \mathrm{BAHIA}$ & $\mathrm{R} \$ 1602,57$ & NORDESTE & (PT) \\
\hline 16 - SERGIPE & $\mathrm{R} \$ 1519,57$ & NORDESTE & (PT) \\
\hline 17ㅇRONDÔNIA & $R \$ 1433,24$ & NORTE & (PPS) \\
\hline 18 MINAS GERAIS & $R \$ 1416,66$ & SUDESTE & (PSDB) \\
\hline 19 SANTA CATARINA & $R \$ 1363,74$ & SUL & (PMDB) \\
\hline 20 PIAUÍ & $R \$ 1340,00$ & NORDESTE & (PT) \\
\hline
\end{tabular}

Fonte: Apeoc. ${ }^{1}$

Figura 2 - Remuneração de professores no Brasil (40 horas-aula): grupo dos seis piores estados

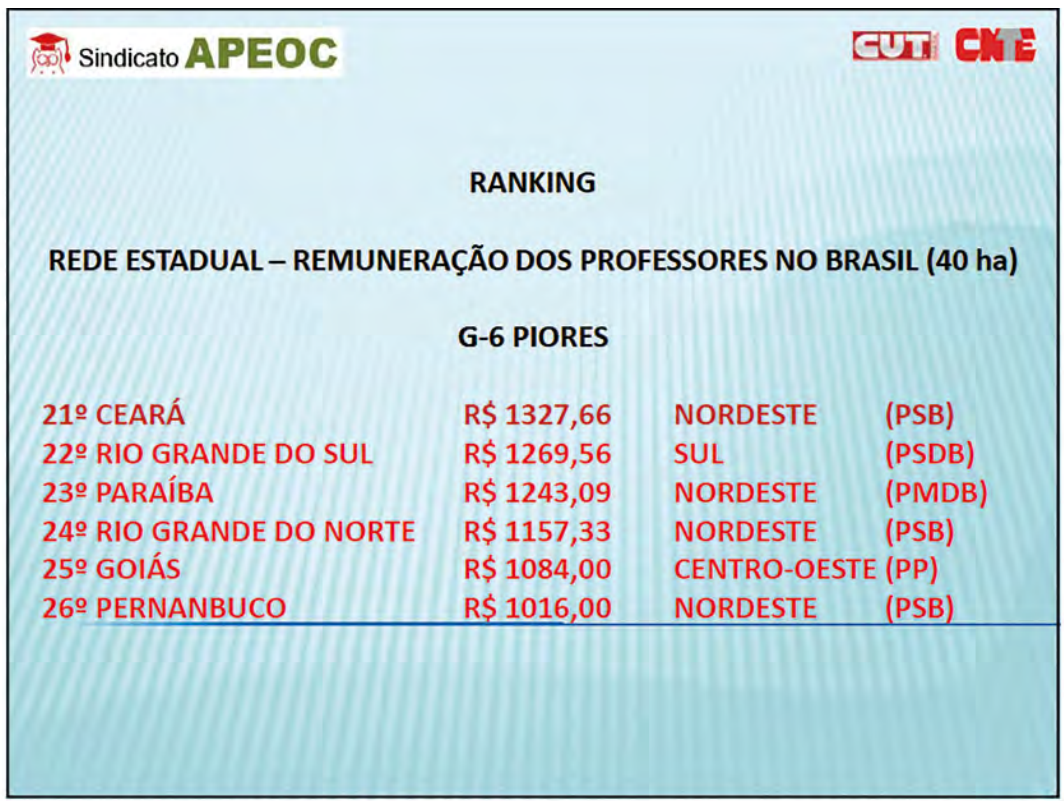

Fonte: Apeoc. ${ }^{2}$ 
É sabido que vários professores se formaram após o ingresso no serviço público de educação, no estado do Tocantins, atendendo à exigência da Lei de Diretrizes e Bases da Educação Nacional (LDBEN), Lei no 9.394/1996, quanto à capacitação no ensino superior para atuar nas diferentes etapas da educação básica em cursos ofertados pela Universidade do Tocantins (Unitins) na graduação em regime especial, sendo essa uma das formas encontradas pelo Estado para solucionar o problema do elevado número de professores sem a formação mínima para atuar nos ensinos fundamental e médio. Para que os professores em exercício pudessem manter suas atividades durante o curso, parte da carga horária dessa capacitação era realizada nos meses de férias escolares (janeiro e julho), e o restante, em encontros aos sábados, domingos e feriados no decorrer do semestre.

A Tabela 1 apresenta o percentual de professores sem a formação mínima no período de 1996 a 2005, o que permite visualizar que ocorre uma redução do percentual de professores sem formação, ou seja, os professores se capacitaram para atuar na educação básica. Do mesmo modo, a Figura 3, com o total de funções docentes com nível superior no Tocantins trabalhando na educação básica, reforça essa informação quanto ao período de 2000 a 2005.

Tabela 1 - Percentual de ocupação sem a formação mínima dos docentes em Tocantins nos ensinos fundamental e médio - 1996-2005

\begin{tabular}{l|c|c|c|c}
\hline \multirow{2}{*}{ Ano } & \multicolumn{2}{|c|}{ Ensino Fundamental } & \multicolumn{2}{c}{ Ensino Médio } \\
\cline { 2 - 5 } & $\begin{array}{c}\text { Funções } \\
\text { Docentes }\end{array}$ & $\begin{array}{c}\text { sem formação } \\
\text { mínima }\end{array}$ & $\begin{array}{c}\text { Funções } \\
\text { Docentes }\end{array}$ & $\begin{array}{c}\text { sem formação } \\
\text { mínima }\end{array}$ \\
\hline 1996 & 8.316 & $56 \%$ & 2.091 & $54 \%$ \\
\hline 2005 & 13.448 & $5 \%$ & 3.794 & $2 \%$ \\
\hline
\end{tabular}

Fonte: Seduc. ${ }^{3}$ 
Figura 3 - Total de funções docentes com nível superior em Tocantins - 2000-2005

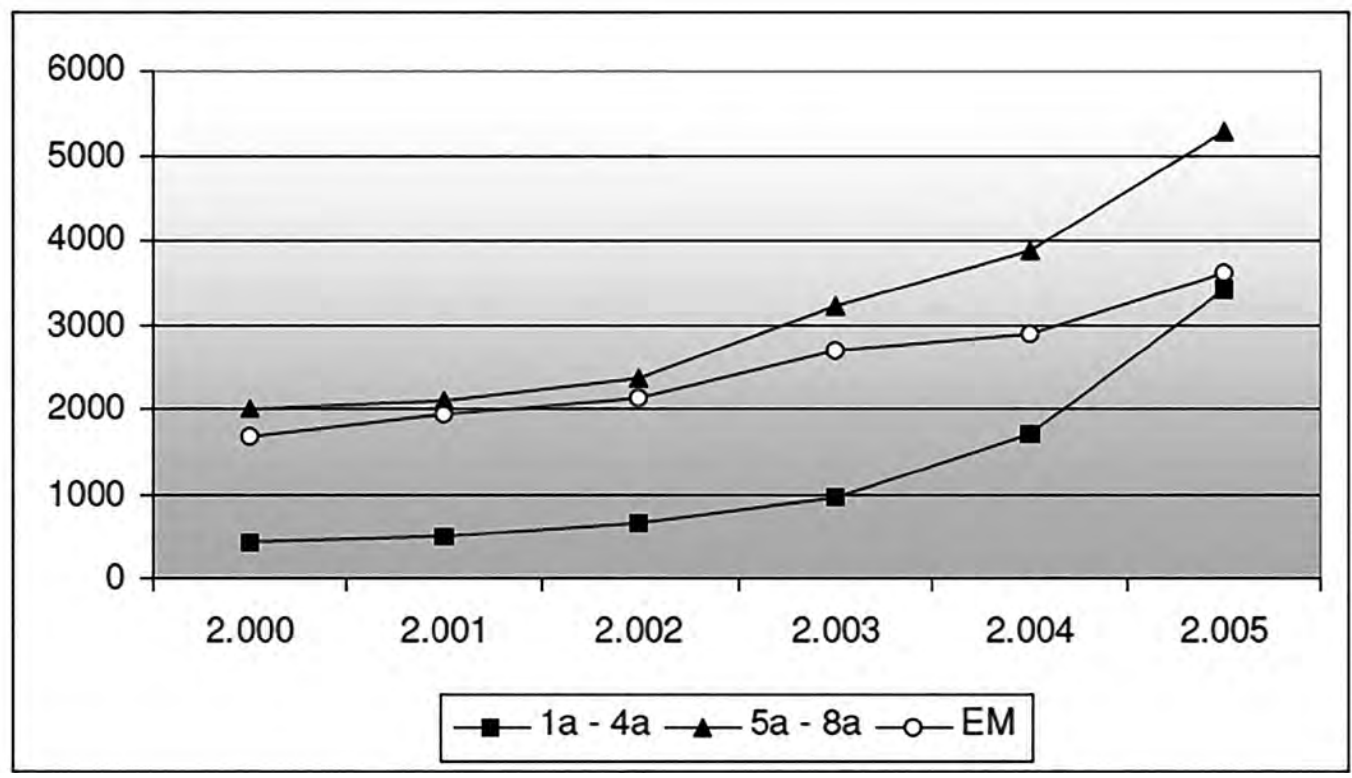

Fonte: MEC. ${ }^{4}$

Os dados apresentados conduzem ao entendimento de que as políticas públicas em torno da formação docente avançaram a partir da instituição da Lei de Diretrizes e Bases da Educação Nacional, Lei nº 9.394/1996. O que se coloca para investigação, no caso de um estado que se formou a partir do norte de outro, é que tal política veio socorrer uma situação caótica de significativos dados sobre a não qualificação docente no antigo norte do estado de Goiás.

Desse modo, o Tocantins, mesmo tendo adotado programas como Programa Escola Autônoma de Gestão Compartilhada (PEAGC), Plano de Desenvolvimento da Escola (PDE) e organização por projeto político-pedagógico nas escolas, hoje, vivencia a situação da maioria das escolas públicas do país, que ainda patinam para resolver problemas relacionados à inclusão de alunos com ou sem necessidades especiais, à gestão, ao currículo e à formação de professores, entre outros. Dificuldades que perpetuaram as relações sociais no interior da escola.

\section{Aspectos políticos que interferiam na gestão da escola}

Desde sempre e até os últimos anos antes da separação que culminou com o nascimento do Tocantins, a região de fronteira não recebia nenhum atendimento, pois todo o material, desde giz, diários de classe (impressos na época), aparato de 
expediente e de limpeza, merenda escolar, etc., passava pela Delegacia Regional de Ensino de Porangatu (estado de Goiás), que, porém, não mais fornecia tais recursos, ficando assim as escolas da região norte (que se tornaria o Tocantins) com atendimento bastante precário.

Esse atendimento precário gerou desmotivação nos gestores, chegando ao extremo de alguns "abandonarem" seus postos, sem o fazerem de fato, ou seja, permaneceram em seus cargos, mas já não atuavam de forma satisfatória.

Apresentamos, a seguir, o relato de um professor entrevistado sobre essa situação em uma escola:

Voltando a 1986, primeiro porque as escolas não tinham autonomia, tudo dependia diretamente do estado, até um pedaço de sabão dependia do estado. E as escolas eram superlotadas, que dificultava muito para o professor trabalhar em sala de aula. Era na faixa de 65 alunos em sala, as escolas não tinham uma estrutura boa para funcionamento porque, além de faltar os materiais necessários para limpeza, não tinha material didático para professor, os alunos não tinham livros, além de os professores não terem material suficiente para ministrar uma boa aula. Era uma escassez de material administrativo, didático e pedagógico (Professor e diretor em escola local).

Na cidade fronteiriça de Palmeirópolis, quando ainda era apenas o estado de Goiás, a organização das escolas era realizada pela Delegacia Regional de Ensino de Porangatu, situada a $140 \mathrm{~km}$ daquela cidade, isso desorganizava a vida escolar, pois, segundo os relatos dos professores, entre outras coisas, fazia-se necessário improvisar com folhas de papel pautado os diários escolares, já que esses só chegavam praticamente no final do ano letivo. A seguir, o relato de outro professor:

Eu, como professor, fui um dos que se recusou a refazer diário no final do $4^{\circ}$ bimestre. Como haviam improvisado não foram refeitos, com exceção de duas professoras. Outro ponto difícil é que tínhamos que ir buscar os materiais quando disponibilizados:"Diretor tinha que se deslocar para buscar esse material lá em Porangatu". Uma fase difícil porque, além de ter superlotação nas escolas e funcionar quatro períodos, contando com o intermediário, não permitindo nem que fizesse limpeza para entrada de outros alunos. Eu trabalhava somente com o ensino médio (antigo segundo grau). Tínhamos cursos técnicos, e eu era professor polivalente. Em Contabilidade, eu lecionava Direito Trabalhista, Economia e Mercado, Mecanografia, Química, Física... teve época que eu trabalhei Português (Língua Portuguesa e Literatura Brasileira) por faltar professores das áreas (Professor de escola da fronteira).

Essa situação, vivenciada quando ainda tratava-se apenas do estado de Goiás, deixou ao Tocantins uma herança de problemas e insatisfações a serem sanados. E isso nos remete à discussão de estrutura administrativa da escola desenvolvida por Paro (2011), que utiliza a elaboração de Antonio Candido ao discutir que estrutura escolar não pode ser entendida apenas no aspecto administrativo. Vincula-se a esse conceito uma visão total da escola, incluindo outros elementos. No caso do estado do Tocantins, teremos que resgatar, além dos elementos políticos de formação do estado, também os elementos constitutivos da educação escolar que se vivenciava 
nos anos 1980, período em que se iniciam as discussões sobre democratização da escola no Brasil. Para entender a discussão sobre a organização escolar no contexto do surgimento do estado do Tocantins, recorremos ao pensamento de Candido:

A estrutura administrativa de uma escola exprime a sua organização no plano consciente e corresponde a uma ordenação racional, deliberada pelo Poder Público. A estrutura total de uma escola é, todavia, algo mais amplo, compreendendo não apenas as relações ordenadas conscientemente, mas, ainda, todas as que derivam da sua existência enquanto grupo social (CANDIDO, 1974, p. 107 apud PARO, 2011, p. 19).

Então, com esse pensamento, podemos afirmar que estão no campo mais amplo as consequências do que vinha ocorrendo nas escolas do Tocantins que levaram a tal situação na estrutura total das escolas, posto que aquilo era da esfera administrativa e expressava a ordenação racional do poder público, portanto, do Estado, que se refletia em situações mais complexas e caóticas no cotidiano do grupo social da escola.

Para maior compreensão dessa ideia, discutiremos a relação de saber/poder que se desenvolvia entre alunos e escola, quando, aproveitando-se da situação caótica que a estrutura demonstrava, criavam relações sociais de barganha para superar as limitações que o sistema educacional local lhes impunha. Ao denominar barganha esse processo, queremos definir a forma estratégica que os alunos encontravam para driblar a péssima condição de ensino a que estavam sujeitos, mesmo que, para isso, enganassem a si mesmos em relação à própria aprendizagem.

\section{Como os alunos constroem a contra-hegemonia no chão da escola}

Talvez se faça necessário apresentar e discutir conceitos que nos são tão caros, quando elaboramos nosso pensamento sobre uma determinada problemática social. O que é, afinal, hegemonia? E de que Estado estamos falando? Trata-se de construir um pensamento crítico a partir de uma reflexão também crítica, fundamentada em Gramsci, que nos mostra o sentido da ação política do aluno e do professor na escola, ou melhor, aquilo que há de político em toda ação humana.

Nesse sentido, resgatamos o pensamento de Gramsci quando defende que o Estado compreende a sociedade política e a sociedade civil, e que esse conceito de Estado alargado veicula a hegemonia da classe dominante, por meio dos aparelhos ideológicos, como igreja, escola e mídia, e dos aparelhos de repressão e regulação jurídicos, mas, também, com a perspectiva contra-hegemônica em geral, nascida no seio da sociedade civil organizada. Para esse autor, o Estado é o guardião porque tem a função de manter a ordem pública e o respeito às leis, mas, além disso, 
é também acionado para regular as relações sociais pela sociedade civil em uma situação de crise.

Da compreensão de Estado como sociedade política mais sociedade civil resulta a colocação de que é na sociedade civil que os trabalhadores se confrontam com sua situação de exploração, uma vez que aí estão os organismos privados de hegemonia dominante. Entretanto, ao trabalhar o conceito de hegemonia, Gramsci considera todo homem um "filósofo" em potencial, capaz de, ao nível da linguagem, do senso comum, do bom senso e da religião popular, elaborar uma contraideologia frente à ideologia dominante (GRAMSCI, 1979, p. 7).

Por conseguinte, faz-se necessário dizer que é neste espaço de hegemonia da classe dominante que os trabalhadores refazem seu conhecimento, do senso comum ao nível da consciência política. Por isso mesmo, trata-se de reconhecer o espaço de luta no qual a sociedade civil se tornou, e sobre o qual fazemos uso do pensamento de Dias: "Um dos erros vitais na análise da sociedade civil é pensá-la como articulação de instituições indiferenciadas, como expressão de interesses universais não contraditórios, sem qualquer caráter classista. Tem-se, assim, uma concepção homogeneizadora, subalternizante" (1997, p. 3).

Essa visão homogeneizante, quando pensamos na educação escolar, provoca uma série de incoerências diante do maior propósito da escola (formar) e produz contradições expressivas das relações sociais que espelham a sociedade da qual se fala. No nível das incoerências, podemos nos referir ao papel de educar. O olhar homogeneizante é incompatível com a alteridade, portanto, não respeita as diferenças, e a consequência se expressa no âmbito das contradições, qual seja, a implementação de um projeto de ensino que propõe uma educação globalizante, uma educação que parte da noção de que todos estão no mesmo ponto de igualdade social, econômica e cultural.

Talvez a origem da escola, segundo Gramsci (1979), explique o aparecimento dessas incoerências e contradições, uma vez que a complexidade da sociedade moderna e o desenvolvimento e a presença das ciências na vida social trataram de criar, para cada atividade prática, uma escola para seus dirigentes e especialistas, gerando, consequentemente, um grupo de especialistas de saber ainda mais elevado para ensinar nessas escolas. Em outras palavras, é o desenvolvimento dessa sociedade, que se organiza segundo as classes, que vai produzir a necessidade da escola e a perspectiva de educação para cada grupo social. É evidente que há aí um projeto político implícito.

Gramsci (1979) anuncia que a divisão fundamental da escola em clássica e profissional foi um esquema racional, pois a escola profissional destinava-se às classes instrumentais, ao passo que a clássica se destinava às classes dominantes 
e aos intelectuais. Esse modelo dual de escola tem um projeto político de formação que se distingue para cada uma dessas classes. Esse modelo dual de escola tem um projeto político de formação que se distingue para cada uma dessas classes. Porém, como a sociedade capitalista foi impulsionada a ofertar a universalização da educação escolar, então, o projeto de formação que servia à escola profissionalizante, pelo menos no princípio instrumental, também foi transportado para a escola pública não profissionalizante. Assim, a perspectiva de educação que ali foi colocada se distanciou de uma formação humana que incluísse uma cultura geral e de visão crítica. Ao contrário, criou as incoerências com um modelo de educação homogeneizante, que se reflete no dia a dia da evasão escolar, dos currículos engessados e da crescente violência simbólica e intelectual que se produz entre os muros escolares.

É dessa escola pública que estamos falando. É da escola que instrumentaliza o ensino em função de um projeto político hegemônico de sociedade, que discutimos ao interpretar a relação dialética entre projetos hegemônicos e contra-hegemônicos vivenciados no interior da escola pública no Brasil, tendo como recorte o Tocantins. Observemos, portanto, no chão dessa escola, um dos exemplos de luta contra-hegemônica.

Durante o ano de 2010, no Colégio Estadual Professora Oneides Rosa de Moura, em Palmeirópolis, Tocantins, espaço de observação desse fenômeno, alguns dos alunos que chegaram ao quarto bimestre letivo sem condições mínimas de aprovação, ao considerar os critérios simples, ou seja, as notas obtidas ao longo do ano, entraram com pedido de transferência na secretaria da unidade escolar sem justificar tal decisão. Soube-se, depois, por colegas, que saíram em busca de chances de aprovação nas cidades vizinhas no estado de Goiás.

Os alunos, filhos de pessoas que transitam entre os dois estados, dizem que, em se tratando de escola pública, é mais fácil de obter nota para aprovação em Goiás. Surgem, assim, justificativas para a busca de uma possibilidade de se sobressair melhor nos resultados de final de ano, considerando que, na época, a média adotada pelas unidades escolares de Goiás era 5,0 pontos, enquanto em Tocantins era 7,0 .

Na escola citada, a única que atendia à clientela do ensino médio na cidade, foi possível constatar a certeza sobre essa prática. No ano seguinte, esses mesmos alunos apresentaram documentação comprobatória para ingressar na série posterior àquela que haviam se transferido, evidenciando situações que precisam ser reavaliadas, pois, em ambos os estados, temos o mesmo papel como escola, qual seja, o de educar. Diante disso, destacam-se algumas indagações: o que foi feito para consecução dessa aprovação? A não aprovação implica que a formação desses alunos está sendo garantida? 
Quando os alunos cruzam as fronteiras espaciais em busca de aprovação escolar, eles estão cruzando também as fronteiras simbólicas das relações sociais de dominação presentes e ausentes entre o Estado (poder) que representa o setor público de cada um dos estados da federação e seus cidadãos, nesse caso específico, representados pelos que praticam a contra-hegemonia.

Há uma cultura escolar que se diferencia em cada ente da federação, fazendo com que o aluno procure barganhar, por meio das notas, o seu objetivo final - a aprovação escolar. Cruzar a fronteira entre esses dois estados já faz parte de suas rotinas, porém, cruzá-la no sentido simbólico de barganha, a fim de usufruir do que o outro lado da fronteira oferece para interesses escusos, é o que se apresenta como novidade, ou como fenômeno de pesquisa. E, no sentido aqui discutido, é um cruzar de fronteira que nega a formação - interesse maior da escola. Essa é uma negação que produz desajustes históricos no perfil do aluno que chegará a universidade, se chegar, pois ele leva consigo um conjunto de déficits sobre conteúdos elementares da cultura geral que deveriam compor sua formação básica. Além disso, ativa o dispositivo do sentido cultural da barganha política na relação: sociedade versus poder público.

É visível, nessa questão, o desejo de burlar regras e poderes. É inevitável que pensemos no sentido da relação contra-hegemônica que os alunos estão construindo com o Estado-poder. Traduzindo isso numa linguagem mais próxima aos alunos, diríamos que a música "Da lama ao caos", de Chico Science e Nação Zumbi, contém uma reflexão sobre essa situação, quando diz: "Posso sair daqui pra me organizar/ Posso sair daqui pra desorganizar/ Posso sair daqui pra me organizar/ Posso sair daqui pra desorganizar/ Da lama ao caos/ Do caos à lama".

Como professores, o que estamos fazendo para evitar o caos? O que estamos fazendo para que nossos alunos não se deparem simplesmente com a lama? E o que podemos exigir do Estado/poder enquanto institucionalidade para nos proporcionar melhores condições de trabalho, a fim de que isso não ocorra?

Tratar dessas peculiaridades nos permite perceber que a educação, hoje, propedêutica, voltada para a preparação da entrada dos alunos na universidade, por meio, principalmente, do Sistema de Avaliação do Ensino Médio (Enem) ou Sistema de Seleção Unificada (Sisu), tem aspectos positivos quanto às determinações de uma formação com base em conteúdos exigidos para esse fim. Contudo, temos a considerar que esse caminho não é a realidade da maioria. Há muitos que se perdem nesse trajeto, pela evasão muito presente na educação básica. Também há aqueles que usam de subterfúgios para tornar possível a conclusão do ensino médio, e é nesse aspecto que construímos a análise deste recorte para pensar as razões que levam um aluno a mudar de escola, de cidade, até de estado, como estratégia 
de "sobrevivência" para chegar a esse resultado. Nesse sentido, constatamos que o cotidiano escolar é identificado pelos alunos como um espaço enfadonho.

Presumimos, também, que o que esteja ocorrendo para impulsionar tais ações venha também de dentro da escola, nas relações sociais de aprendizagem, em um processo de ensino e aprendizagem que não está dialogando com os aspectos da conjuntura política, social e histórica, que põe todos no contexto do descaso e desrespeito a que o norte do estado foi submetido. É indiscutível que o estado do Tocantins surge sob a égide da subserviência política, que traz o ranço do clientelismo, que a classe política é quase que totalmente oriunda da classe social proprietária de terra, daí os sistemas de subserviência se manterem e se refletirem em todas as instituições locais.

$\mathrm{Na}$ escola, constatamos que o sistema de reprodução das relações de dominação se faz pelo currículo, por meio dos componentes curriculares, dos conteúdos, da espacialidade da escola, das normas e regras instituídas, das exigências sobre a corporeidade humana e sobre o comportamento definido para cada sujeito escolar (merendeira, professor, aluno, coordenador, etc.). Freire (1996) questiona essa lógica e demonstra como pensa um educador conservador que defende tal escola:

Por que não estabelecer uma necessária "intimidade" entre os saberes curriculares fundamentais aos alunos e a experiência social que eles têm como indivíduos? Por que não discutir as implicações políticas e ideológicas de um tal descaso dos dominantes pelas áreas pobres da cidade? A ética de classe embutida neste descaso? Porque, dirá um educador reacionariamente pragmático, a escola não tem nada que ver com isso. A escola não é partido. Ela tem que ensinar os conteúdos, transferi-los aos alunos. Aprendidos, estes operam por si mesmos (FREIRE, 1996, p. 15, grifo nosso).

É esse pensamento do educador reacionariamente pragmático que embasou a ideia de que a escola é neutra, e é essa ideia que forja uma proposta de autonomia para a qual o aluno ainda não está pronto a vivenciar, visto que ele ainda não adquiriu os códigos de linguagem e o conhecimento histórico que ressignificam sua condição de sujeito daquela sociedade.

A escola é a instituição que deve transmitir os saberes históricos de uma sociedade e, também, contribuir com a disseminação dos códigos e instrumentos de linguagem de uma dada cultura. $\mathrm{E}$ isso se faz por meio do trabalho pedagógico que se ritualiza na aula, no espaço da sala de aula, na efetivação do currículo. É um trabalho que implica relações sociais entre sujeitos distintos. O trabalho pedagógico impõe à escola um grande dilema diante da sociedade de classe, qual seja, ele não se materializa em um produto.

Talvez por isso a escola, em especial a pública, sofra essa imposição de neutralidade, essa indução de ter que estar distante da ação política. Porém, a escola 
pública tem um papel importante nas relações sociais e políticas, que é o de publicizar os significados da prática social em que os sujeitos sociais se constituíram.

A análise que Gramsci faz para entender a organização da escola e da cultura, quando explica o nível de especialização que se criou no sistema capitalista e que incidiu sobre a escola em termos de exigência, corresponde ao que estamos referendando quando falamos sobre a função social da escola de estabelecer relação com a prática social. Gramsci (1979) discute que, ao lado de uma escola humanista - que teria como função: estender, discutir e apresentar a cultura geral -, o poder de reflexão dos alunos e de orientação sobre a vida também fez surgir uma escola particular e direcionada às especialidades que a sociedade de classe criou. $\mathrm{E}$ isso causou uma crise na organização escolar. Salvo as devidas diferenças históricas e conjunturais em que Gramsci se baseava, acreditamos ser essa análise um exemplo do que ocorre com a estrutura escolar da região de fronteira observada, além disso, em um sentido mais amplo, ela reflete sobre o que ainda ocorre com a educação básica no Brasil.

\section{Considerações finais}

A fronteira entre os estados de Tocantins e Goiás se caracteriza, antes de tudo, por uma memória sobre a história política que fez surgir o novo estado, que foi criado por força de interesses políticos de um grupo social ligado aos negócios dos ramos da pecuária e da agricultura. Isso é visível até hoje, dado o grupo político que se mantém no poder. Entretanto, não há como negar a imensa insatisfação dos moradores da antiga região norte do estado de Goiás, que se sentiram bastante abandonados pelo poder público e engrossaram as fileiras no projeto de construção do novo estado.

Diante da conjuntura que expressa a história daquele lugar, é compreensível, porém não aceitável, o descaso com a educação. A vida escolar das crianças daquela região foi sempre relegada a donativos que, em geral, só surgiam em períodos eleitorais.

Nesse quadro, tanto professores quanto alunos têm buscado suas saídas contra-hegemônicas ao poder instituído via escola. Os professores buscam suas capacitações no estado de Goiás cruzando fronteira, porém, é um deslocamento temporário em função de melhorar as condições de estudo, trabalho e capacitação, visando a uma melhor remuneração. Os alunos, sentindo-se fragilizados com um estudo precarizado por tudo que fora imposto, até então, ao norte do antigo estado e ao sul do atual, experimentam os benefícios que o cruzamento de fronteiras pode lhes proporcionar. Para os alunos, a cultura escolar da fronteira se apresenta com duas 
possibilidades: cruzar a fronteira e conquistar as notas para aprovação escolar e, depois, retornar ao seu lugar de origem, ou não se deslocar e viver as dificuldades da imobilidade social que a reprovação lhes impõe.

Considerando que se trata de escola pública e que sua função é possibilitar que cada pessoa encontre meios de se desenvolver como cidadão, no sentido mais amplo que essa palavra possa significar, os entraves apresentados para a educação básica, como abandono e evasão, além de um grande número de jovens e adultos que nem chegam a se matricular, colocam-nos diante de dilemas que precisam ser repensados, como a condução do currículo e a forma como esses jovens são vistos por nós professores. Há muito a ser feito para que a escola se aproxime daquilo que já vem sendo defendido desde o século passado por educadores como Gramsci.

\section{Notas}

1 Disponível em: <www.apeoc.org.br/extra/pesquisa.salarial.apeoc.pdf>. Acesso em: 02 nov. 2014.

2 Disponível em: <www.apeoc.org.br/extra/pesquisa.salarial.apeoc.pdf>. Acesso em: 02 nov. 2014.

3 Disponível em: <www.maxwell.vrac.puc-rio.br/11066/11066_4.PDF>. Acesso em: 02 nov. 2014.

4 Disponível em: <www.maxwell.vrac.puc-rio.br/11066/11066_4.PDF>. Acesso em: 02 nov. 2014.

\section{Referências}

DA LAMA ao Caos. Chico Science e Nação Zumbi. 2003-2017. Disponível em: <https://www. letras.mus.br/chico-science/108267>. Acesso em: 05 jan. 2014.

DIAS, Edmundo. A liberdade (im)possivel na ordem do capital - reestruturação produtiva e passivização. Campinas: IFCH/Unicamp, 1997. (Textos Didáticos).

FARAGE, Nadia. As muralhas dos sertões: os povos indígenas no rio Branco e a colonização. Rio de janeiro: Paz e Terra; ANPOCS, 1991.

FREIRE, Paulo. Pedagogia da autonomia: saberes necessários à prática educativa. São Paulo: Paz e Terra, 1996. (Coleção Leitura).

GRAMSCI, Antonio. Os intelectuais e a organização da cultura. 3. ed. Trad. Carlos Nelson Coutinho. Rio de Janeiro: Civilização Brasileira, 1979.

PARO, Vitor Henrique. Crítica da estrutura da escola. São Paulo: Cortez, 2011.

PEREIRA, Mariana Cunha. Processos migratórios na fronteira Brasil-Guiana. Estudos Avançados, São Paulo, v. 20, p. 209219, 2006.

SANTILLI, Paulo. Pemongon Pata: território Macuxí. Rotas de conflito. São Paulo: Editora Unesp, 2001. 